\title{
AN EXPERIMENTAL STUDY ON PROGRESSIVE WAVE-INDUCED STRESSES DURATION IN SEABED SOIL
}

\section{Shang-Chun Chang}

Ph.D. Candidate, Department of Harbor and River Engineering, National Taiwan Ocean University, 2, Pei-Ning Road Keelung, Taiwan 20224, R.O.C, D88520003@mail.ntou.edu.tw

Lien-Kwei Chien

Professor, Department of Harbor and River Engineering, National Taiwan Ocean University, 2, Pei-Ning Road Keelung, Taiwan 20224, R.O.C.

Jaw-Guei Lin Associate Professor, Department of Harbor and River Engineering, National Taiwan Ocean University, 2, Pei-Ning Road Keelung, Taiwan 20224, R.O.C.

Yung-Feng Chiu

Director, Harbor and Marine Technology Center, 2, Chung-Heng 10th Road Wuchi, Taichung, Taiwan 435, R.O.C.

Follow this and additional works at: https://jmstt.ntou.edu.tw/journal

Part of the Civil and Environmental Engineering Commons

\section{Recommended Citation}

Chang, Shang-Chun; Chien, Lien-Kwei; Lin, Jaw-Guei; and Chiu, Yung-Feng (2007) "AN EXPERIMENTAL STUDY ON PROGRESSIVE WAVE-INDUCED STRESSES DURATION IN SEABED SOIL," Journal of Marine Science and Technology.

Vol. 15: Iss. 2, Article 8.

DOI: $10.51400 / 2709-6998.2041$

Available at: https://jmstt.ntou.edu.tw/journal/vol15/iss2/8

This Research Article is brought to you for free and open access by Journal of Marine Science and Technology. It has been accepted for inclusion in Journal of Marine Science and Technology by an authorized editor of Journal of Marine Science and Technology. 


\section{AN EXPERIMENTAL STUDY ON PROGRESSIVE WAVE-INDUCED STRESSES DURATION IN SEABED SOIL}

\section{Acknowledgements}

This research was funding by National Science Council, Taiwan under the project entitled "The Study of the Dynamic Behavior in Nearshore Structures beneath Foundation Soil Due to Wave Loading Action (I) " with project number of NSC-91-2211-E-019-013, and with the cooperation of the Harbor and Marine Technology Center. The authors want to express their sincerely appreciations to all of them. 


\title{
AN EXPERIMENTAL STUDY ON PROGRESSIVE WAVE-INDUCED STRESSES DURATION IN SEABED SOIL
}

\author{
Shang-Chun Chang*, Lien-Kwei Chien**, Jaw-Guei Lin***, and Yung-Feng Chiu****
}

Key words: wave-induced stresses, stress path, phase shifts, hydraulic model test.

\begin{abstract}
The total stress behavior in seabed soil induced by progressive waves was investigated in time sequence through the experiments in a wave flume. The static stress measurements show that the natural deposit seabed retains an initial shear stress that reduces the resistance capacity of shear strength of the soil. The dynamic stress measurements show that, by comparing with seabed surface pressure, the vertical stress, horizontal stress, and pore water pressure are found to have different phase shifts. Such phase shifts strongly affect the duration behavior of the total stresses of the soil and different from the current theories that assume the waves and pressures in seabed are synchronous, the influences on the seabed stability should be taken into account.
\end{abstract}

\section{INTRODUCTION}

Usually, the most serious but occasional natural disaster in coastal zone is the invasion of typhoon or hurricane. From the investigation of natural disaster in the past few decades around the world, the wave-induced disasters in coastal zone can be classified into failures of seabed instability and failures of coastal structure. Their failure mechanisms are mostly caused by the liquefaction and shear failure of the seabed soil [19], and thus lead to the related researches all focus on the topics of wave-induced dynamic stresses in a permeable seabed and the resistance shear strength of seabed soil.

Paper Submitted 04/13/06, Accepted 05/16/06. Author for Correspondence: Shang-Chun Chang. E-mail:D88520003@mail.ntou.edu.tw.

*Ph.D. Candidate, Department of Harbor and River Engineering, National Taiwan Ocean University, 2, Pei-Ning Road Keelung, Taiwan 20224, R.O.C.

**Professor, Department of Harbor and River Engineering, National Taiwan Ocean University, 2, Pei-Ning Road Keelung, Taiwan 20224, R.O.C.

***Associate Professor, Department of Harbor and River Engineering, National Taiwan Ocean University, 2, Pei-Ning Road Keelung, Taiwan 20224, R.O.C.

****Director, Harbor and Marine Technology Center, 2, Chung-Heng 10th Road Wuchi, Taichung, Taiwan 435, R.O.C.
Jeng [5] revised the past researches about the progressive wave-induced dynamic stresses in seabed, and classified into two major branches: theoretical approaches and experimental approaches. The theoretical approaches are mainly based on the general theory of three dimensional consolidation proposed by Biot [1], different wave types (linear or nonlinear wave) and porous seabed media properties (infinite or finite depth, completely saturated or partially saturated, isotropic or cross-anisotropic, homogeneous or non-homogeneous, poro-elastic or poro-elastoplastic, variation of Young's modulus $E$, shear modulus $G$, Poisson's ratio $v$ and coefficient of permeability $k$ had been introduced into different models (un-coupled model/drained model, consolidation model/quasi-static model, dynamic model and poro-elastoplastic model) to find the analytical or numerical solutions. Under the assumptions of infinite depth, fully saturated, homogeneous, isotropic and compressible pore fluid in compressible porous media, Yamamoto et al. [17] and Madsen [11] were first derived a closed form analytical solution for linear wave-induced pore pressure, soil displacement and effective stresses in seabed. After then, more comprehensive researches for the analytical solution had been proposed, such as Seymour et al. [15], Jeng and Seymour [7] and Kitano and Mase [8] considered the soil is unsaturated, anisotropic and with inhomogeneous permeability; Jeng [4] and Yuhi and Ishida [18] considered the soil with cross-anisotropic behavior; Lee et al. [10] considered the Coulomb-damped poroelastic seabed and Jeng and Cha [6] taken into account the waves as nonlinear.

On the other hand, in experimental approaches, the researches can be distinguished into two parts: field measurements and laboratory experiments. In field measurement studies, Okusa and Uchida [13], Okusa [12] and Zen and Yamazaki [22] collected and analyzed the field data of pressure at seabed surface and pore water pressure, vertical and horizontal total stresses in seabed, and compared with their theoretical results. In laboratory experiment studies, Yamamoto et al. [17] and Tsui and Helfrich [16] studied the pore pressure in 
seabed induced by progressive waves in wave flumes, and compared with the results derived from linear wave theory and stokes' $2^{\text {nd }}$ order wave theory. Demars and Vanover [2] investigated in a wave flume about seabed displacements, pore water pressure, vertical and horizontal total stresses in seabed, and compared with theories. In order to reduce the scale effect, Zen and Yamazaki [20,21] developed a compressive testing apparatus to study the wave-induced pore pressure in seabed. Sassa and Sekiguchi [14] used the centrifugal wave experiments to study the excitation of pore pressure in seabed, and seabed liquefaction under the action of progressive waves or standing waves.

From all above relevant studies, one may find that the theory of progressive wave-induced stresses in seabed have been developed well, and a vast amount of field data and experimental data to confirm the theory. However, no discussion can be found about the duration behavior of the total stresses acting on the seabed soil, thus leads to the motive of this research to carry out a series of hydraulic model tests in a wave flume about progressive wave-induced durational behavior of dynamic pore water pressure, vertical total stress and horizontal total stress in seabed.

\section{EXPERIMENTAL SETUP}

The experiments were carried out in the wave flume (Length:Width:Height $=100 \mathrm{~m}: 1.5 \mathrm{~m}: 2 \mathrm{~m}$ ) in Harbor and Marine Technology Center at Taichung, Taiwan. Figure 1 shows the layout of the movable seabed model. At the near side of the wave paddle, a fixed bed with 1: 10 slope adjacent to a $2 \mathrm{~m}$ long platform was set in front of a sand trench. Behind the sand trench, a $1.2 \mathrm{~m}$ long platform was set to retain the trench. The sand trench (Length:Width:Depth $=5.5 \mathrm{~m}: 1.5 \mathrm{~m}: 0.6 \mathrm{~m}$ ) is used to contain the movable seabed. The water depth is $52.6 \mathrm{~cm}(h)$ above the movable seabed and is $112.6 \mathrm{~cm}\left(h_{0}\right)$ in front of the wave paddle. The seabed material was a uniform, round grained, fine sand and is classified as SP according to the Unified Soil Classification System. The physical properties of the soil samples are listed in Table 1. The deployment method of the material was pluviation through water method, with 12 hours self consolidation.

In this study, the movable seabed model of experiments was setup in three phases. Phase I was focused on the measurements of the pressure at seabed surface and the pore water pressure in shallower seabed with single test. Figure 2 shows that the sensors were deployed at

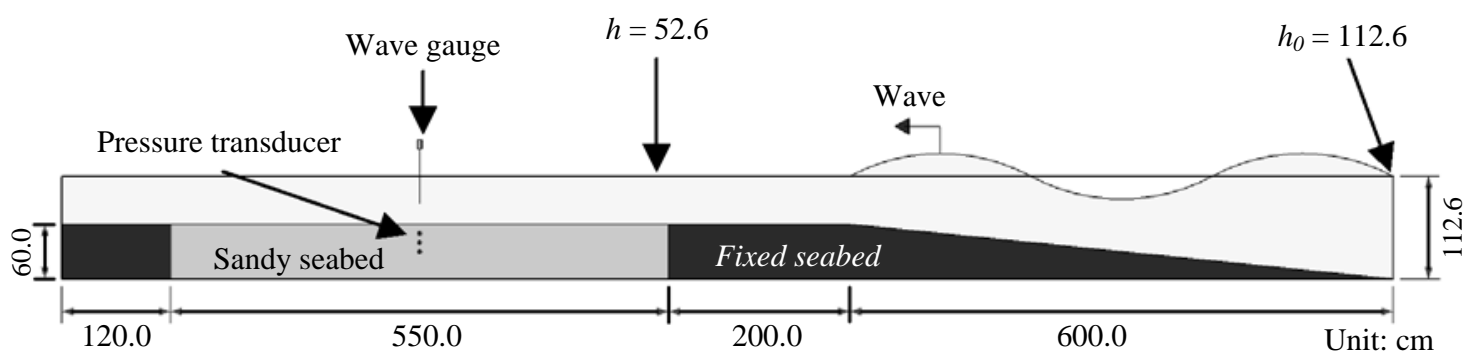

Fig. 1. Layout of movable seabed model.

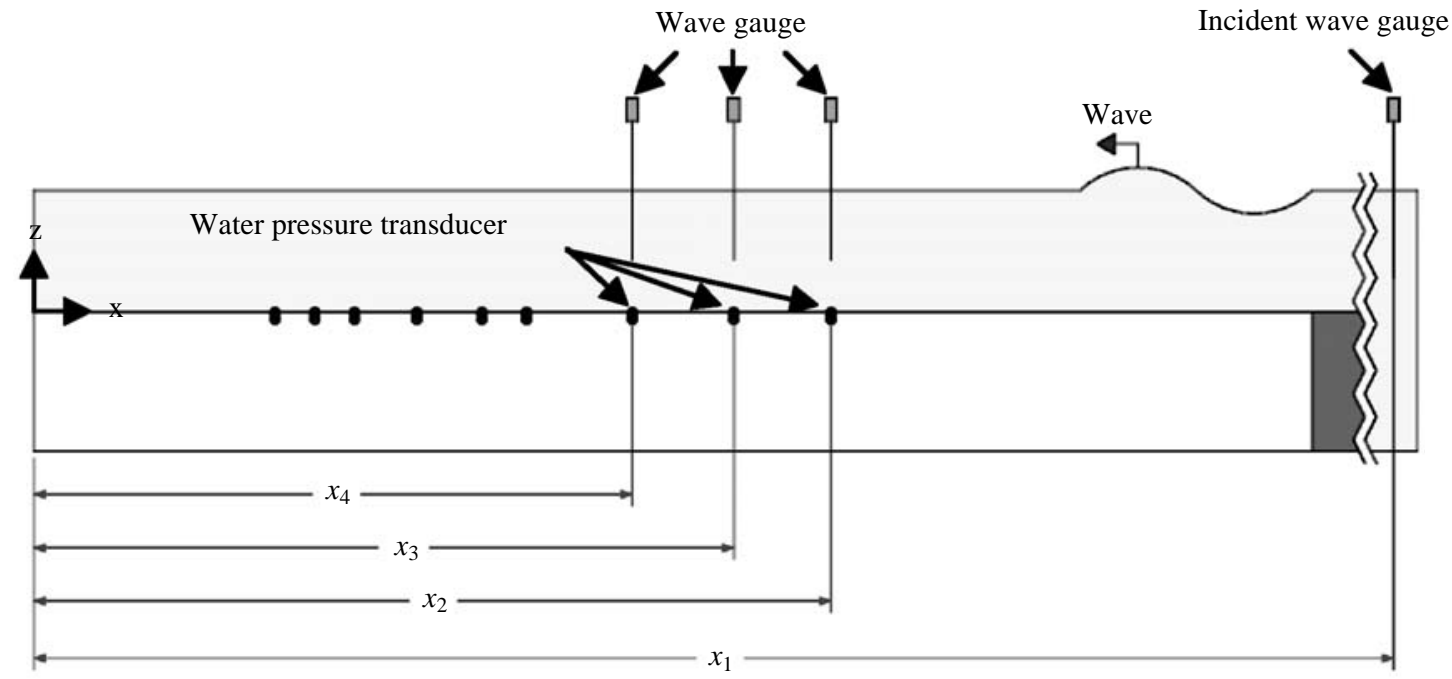

Fig. 2. Layout of seabed surface pressure and shallow pore water pressure measurement. 
Table 1. Physical properties of the seabed soil

\begin{tabular}{lc}
\hline Specific gravity, $G_{s}$ & 2.654 \\
\hline Maximum dry density, $\gamma_{d_{\max }}\left(\mathrm{g} / \mathrm{cm}^{3}\right)$ & 1.607 \\
Minimum dry density, $\gamma_{d_{\min }}\left(\mathrm{g} / \mathrm{cm}^{3}\right)$ & 1.286 \\
Mean diameter, $D_{50}(\mathrm{~mm})$ & 0.220 \\
Coefficient of uniform, $C_{u}$ & 2.415 \\
Coefficient of curvature, $C_{c}$ & 0.932 \\
USCS classification & $\mathrm{SP}$ \\
\hline
\end{tabular}

$\mathrm{z}=0 \mathrm{~cm},-1 \mathrm{~cm}$ and $-3 \mathrm{~cm}$ measured from the seabed surface. Phase II was focused on the measurements of the vertical stress, the horizontal stress and the pore water pressure in seabed with six tests. Figure 3 shows that the sensors were deployed at $-10 \mathrm{~cm},-20 \mathrm{~cm}$ and $-30 \mathrm{~cm}$. Phase III was focused on the measurements of the pore water pressure in seabed with single test. Figure 4 shows that the sensors were deployed from $\mathrm{z}=$ $-5 \mathrm{~cm}$ to $\mathrm{z}=-45 \mathrm{~cm}$ with interval of $5 \mathrm{~cm}$. In each test, the horizontal locations of the sensor are different as shown in Table 2. With the origin at seabed surface, the horizontal axis is positive to the right (i.e. to the wave paddle) and the vertical axis is positive upwardly. Capacitance wave gauge was set at each horizontal location of the sensors to measure the water wave, and another wave gauge was set outside the slopping bottom to measure the incident waves. The measure range of the capacitance wave gauge used in the experiments is $60 \mathrm{~cm}$, and the pressure transducer contains two types: $20 \mathrm{kPa}\left(200 \mathrm{~g} / \mathrm{cm}^{2}\right.$, for horizontal and pore water stresses) and $50 \mathrm{kPa}\left(500 \mathrm{~g} / \mathrm{cm}^{2}\right.$, for vertical stresses) in capacity, and the resolutions are $0.0056 \mathrm{kPa}\left(0.057 \mathrm{~g} / \mathrm{cm}^{2}\right)$ and $0.0111 \mathrm{kPa}\left(0.115 \mathrm{~g} / \mathrm{cm}^{2}\right)$, respectively.

Ten no-breaking regular wave conditions were
Table 2. Horizontal location of sensors in each testing case

\begin{tabular}{cccccc}
\hline Phase no. Test case no. & $x_{1}(\mathrm{~cm})$ & $x_{2}(\mathrm{~cm})$ & $x_{3}(\mathrm{~cm})$ & $x_{4}(\mathrm{~cm})$ \\
\hline 1 & 1 & 1420 & 343.0 & 301.1 & 257.5 \\
\hline \multirow{4}{*}{2} & 2 & 1420 & 120.9 & 103.8 & 86.7 \\
& 3 & 1420 & 192.8 & 164.8 & 138.0 \\
& 4 & 1420 & 250.0 & 231.0 & 212.0 \\
& 5 & 1420 & 318.3 & 287.9 & 257.5 \\
& 6 & 1420 & 383.7 & 342.4 & 301.1 \\
\hline 3 & 7 & 1420 & 446.5 & 394.7 & 343.0 \\
\hline
\end{tabular}

employed in each test to simulate the practical waves from ordinary waves to severe waves with a reference scale of 1:36. In each test case, all wave conditions were carried out from small wave condition to large wave condition. Table 3 shows the sequence of testing wave conditions and the time duration.

All sensors, including pressure sensors and wave gauges, are recorded synchronously to obtain the related water surface fluctuations and dynamic pressure in seabed. After all wave conditions are tested, the sandy seabed and all sensors were re-deployed to retain the natural deposited property of the sandy seabed for the next case.

\section{INITIAL STATIC STRESSES AND DYNAMIC STRESSES IN SEABED}

\section{Initial static stresses in seabed}

In Case 2 to Case 7, the initial static stresses, the

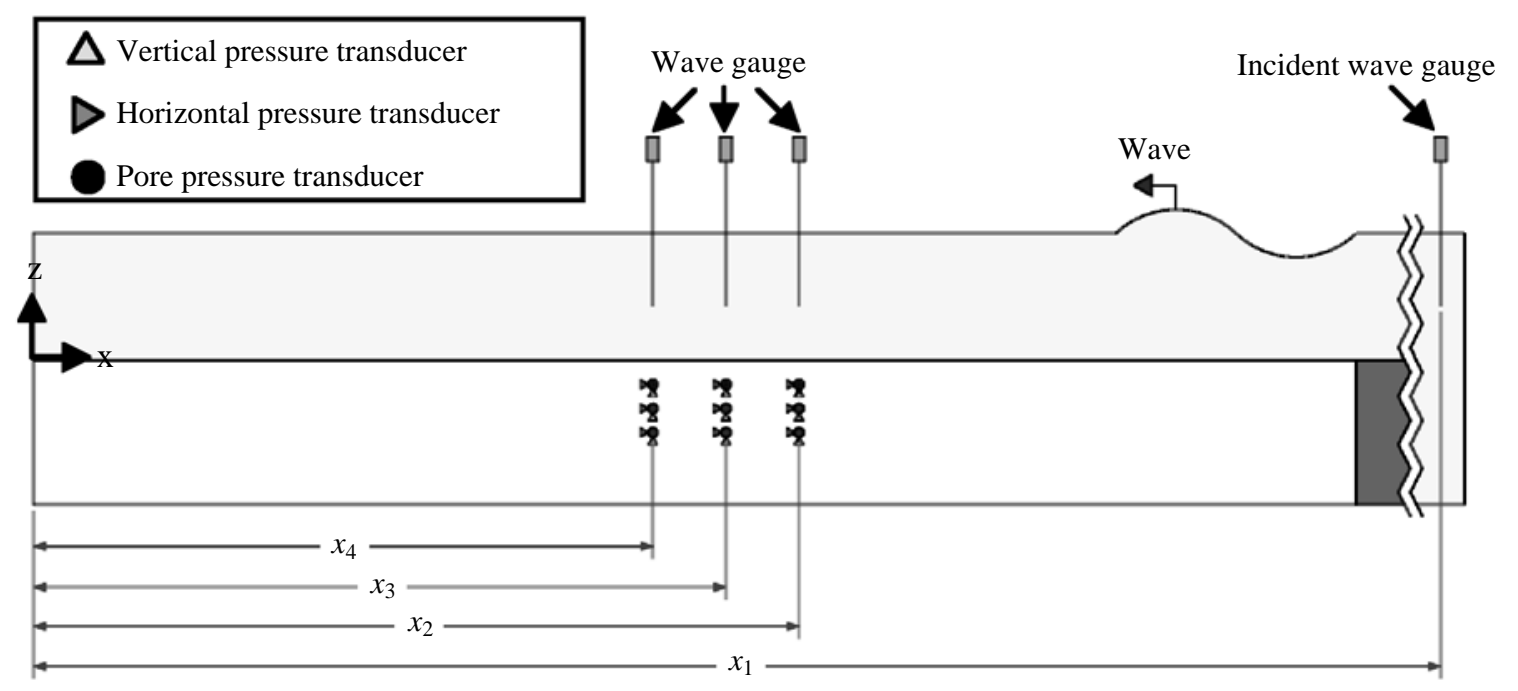

Fig. 3. Layout of seabed stresses measurement. 
Table 3. Experimental sequence and time duration

\begin{tabular}{|c|c|c|c|c|}
\hline \multirow{2}{*}{ No. } & \multicolumn{2}{|c|}{ Wave condition } & \multirow{2}{*}{ Code } & \multirow{2}{*}{$\begin{array}{c}\text { Time duration } \\
\text { (s) }\end{array}$} \\
\hline & $\mathrm{H}(\mathrm{cm})$ & $\mathrm{T}(\mathrm{s})$ & & \\
\hline 1 & 8.33 & 1.00 & H08T10 & 140 \\
\hline 2 & 8.33 & 1.33 & H08T13 & 110 \\
\hline 3 & 13.89 & 1.33 & H13T13 & 110 \\
\hline 4 & 8.33 & 1.67 & H08T16 & 100 \\
\hline 5 & 13.89 & 1.67 & H13T16 & 100 \\
\hline 6 & 19.44 & 1.67 & H19T16 & 100 \\
\hline 7 & 8.33 & 2.00 & H08T20 & 90 \\
\hline 8 & 13.89 & 2.00 & H13T20 & 90 \\
\hline 9 & 19.44 & 2.00 & H19T20 & 90 \\
\hline 10 & 25.00 & 2.00 & H25T20 & 90 \\
\hline
\end{tabular}

effective vertical stress $\sigma_{v_{s}}^{\prime}$ and the effective horizontal stress $\sigma_{h_{s}}^{\prime}$, were calculated from the measurement of vertical and horizontal stresses before and after the preparation of seabed to explore the characteristics of natural deposited seabed. The results are shown in Table 4. From the Table, the coefficient of earth pressure $\left(K=\sigma_{v_{s}}^{\prime} / \sigma_{h_{s}}^{\prime}\right)$ is found not equal to 1 . The average coefficient of earth pressure $\left(K_{\text {ave }}\right)$ decreases as depth increases which means an initial shear stress $\left(\left(\sigma_{v_{s}}^{\prime}-\right.\right.$ $\left.\sigma_{h_{S}}^{\prime}\right) / 2$ ) exist in the soil without wave action, and the deeper seabed soil sustains larger initial shear stress. Thus, the dynamic resistant strength of seabed soil under the wave action should be considered the residual amount after subtracting the initial shear stress from soil strength.

\section{Progressive wave-induced dynamic stresses in seabed}

The dynamic stresses induced by progressive waves are discussed in following sequence: wave above the seabed, dynamic pressure at seabed surface, and dynamic stress in seabed. Zero-up-crossing method proposed by Goda [3] was employed to identify the individual waves' amplitude and related wave period in both wave and pressure records.

\section{(1) Wave above the seabed}

By introducing the normalized wave parameter $H / g T^{2}$ of all individual wave heights $H$ and related wave periods $T$ from all records and normalized water depth $h / g T^{2}$ into the diagram of ranges of suitability for various theories proposed by Le Méhauté [9], where $h$ is water depth and $g$ is gravitational acceleration. Figure 5 shows that the experimental waves are mostly lie in the range of Stokes' $2^{\text {nd }}$ order wave theory, except for the case of H19T16 fits in the range of Stokes' $3^{\text {rd }}$ order

Table 4. Measured initial static stresses in seabed

\begin{tabular}{|c|c|c|c|c|}
\hline $\begin{array}{c}\mathrm{z} \\
(\mathrm{cm})\end{array}$ & $\begin{array}{c}\sigma_{v_{s}}^{\prime} \\
\left(\mathrm{N} / \mathrm{m}^{2}\right)\end{array}$ & $\begin{array}{c}\sigma_{h_{S}}^{\prime} \\
\left(\mathrm{N} / \mathrm{m}^{2}\right)\end{array}$ & $K$ & $K_{\text {ave }}$ \\
\hline-10 & $561.6 \sim 635.4$ & $590.1 \sim 603.8$ & $0.950 \sim 1.051$ & 0.983 \\
\hline-20 & $842.1 \sim 1353.0$ & $719.6 \sim 1202.4$ & $0.854 \sim 0.889$ & 0.872 \\
\hline-30 & $1589.6 \sim 1923.5$ & $920.9 \sim 1354.7$ & $0.479 \sim 0.852$ & 0.676 \\
\hline
\end{tabular}

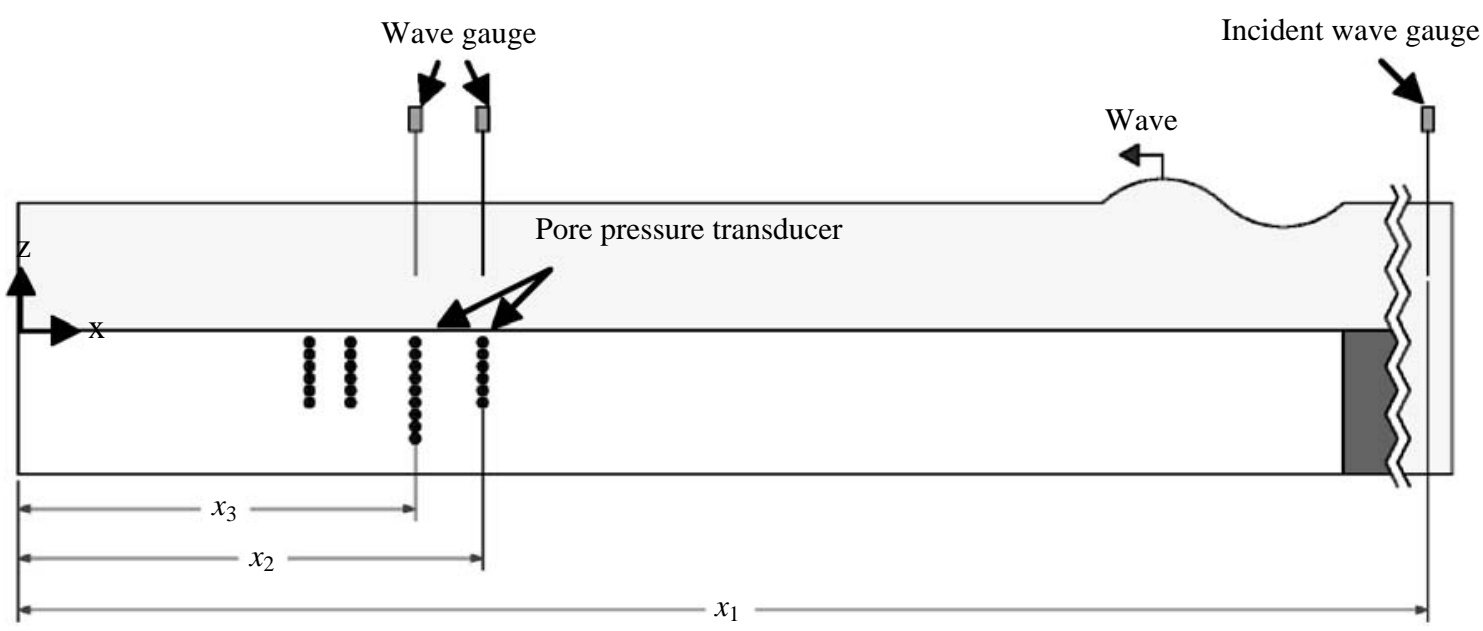

Fig. 4. Layout of seabed pore pressure measurement. 


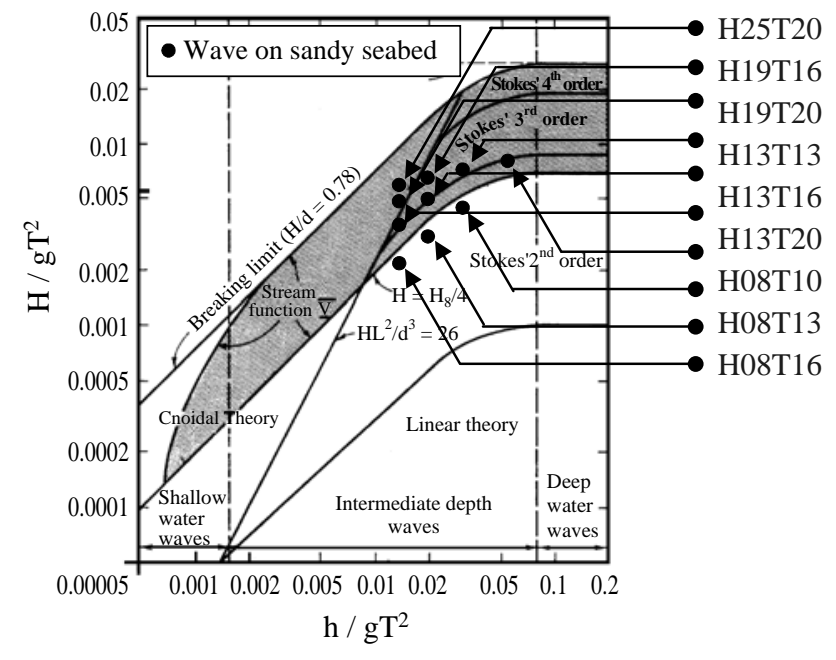

Fig. 5. Wave theory check of experimental waves.

wave theory and the cases of H19T20 and H25T20 fit in the range of Cnoidal wave theory. Thus, Stokes' $2^{\text {nd }}$ order wave theory is used in this study for simplicity. Eqs. (1) and (2) show the theoretical progressive water wave $\eta$ and wave pressure $p$ at seabed surface.

$$
\begin{aligned}
\eta & =\frac{H}{2} \cos (k x+\omega t) \\
& +\frac{\pi H^{2}}{8 L} \frac{\cosh (k h)}{\sinh ^{3}(k h)}[2+\cosh (2 k h)] \cos [2(k x+\omega t)] \\
p & =\frac{\rho g H}{2} \frac{1}{\cosh (k h)} \cos (k x+\omega t) \\
& +\frac{3 \rho g \pi H^{2}}{4 L} \frac{1}{\sinh (2 k h)}\left[\frac{1}{\sinh ^{2}(k h)}-\frac{1}{3}\right] \cos [2(k x+\omega t)]
\end{aligned}
$$

where $L$ is the wave length, $\rho$ is the water density, $k=$ $2 \pi / T$ is the wave number, $x$ is the horizontal coordinate, $\omega=2 \pi / L$ is the angular frequency, and $t$ is time.

\section{(2) Dynamic pressure at seabed surface}

From the literature review, the present theories about the progressive wave-induced dynamic stresses in seabed are all using the pressure at the seabed surface $p$ as the normalization parameter under the assumption that all stresses and pressures are synchronously. Therefore, this section will first discuss the occurrence times and magnitudes of the characteristic nodes including the crest, trough and zero-down-crossing node (Z-D-C) of water wave and wave pressure profile at seabed surface in Case 1 (as shown in Figure 2).

Figure 6 compares the absolute value of maximum/minimum wave pressure $\left(p_{C} / p_{T}\right)$ at seabed surface with the relative theoretical value $\left(p_{T C} / p_{T T}\right)$ from all test cases. The theoretical data is found similar to experimental data in small wave conditions, but overestimate in large wave conditions, especially during the wave crest action. The difference between them is that the theory assumes the seabed is rigid and impermeable, however the seabed in the experiments is compressible and permeable sandy seabed that larger waves might cause the larger energy loss due to the deformation of seabed and friction between pore water and soil particle.

From the results shown in Figure 6, the corrections of the extreme wave pressure at seabed surface could be expressed as follows:

$$
p_{c c}=-0.0002337 \cdot p_{T C}^{2}+0.9685 \cdot p_{T C}
$$

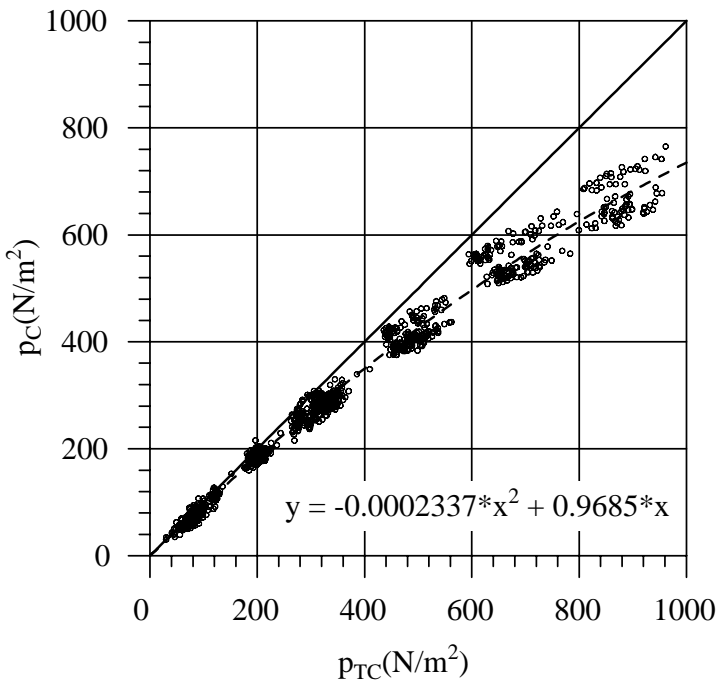

(a) Wave crest

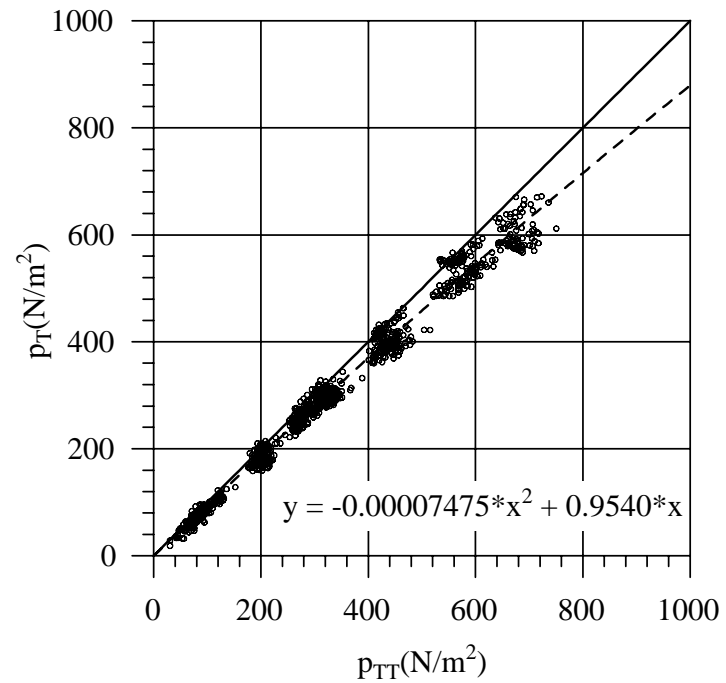

(b) Wave trough

Fig. 6. Comparisons of experimental and theoretical pressures at the seabed surface. 


$$
p_{c t}=-0.00007475 \cdot p_{T T}^{2}+0.9540 \cdot p_{T T}
$$

where, $p_{c c}$ and $p_{c t}$ are respectively the corrected wave pressure at seabed surface as wave crest and wave trough actions.

In order to evaluate the synchronicity of water waves and pressures at seabed surface, phase shift between the occurrence times of the characteristic nodes on both time series is calculated by the follow equation.

$$
\theta=\frac{2 \pi \cdot\left(t_{p}-t_{w}\right)}{T}
$$

where, $\theta$ is the phase shift of seabed surface pressure with respect to water wave, $t_{w}$ and $t_{p}$ are respectively the occurrence times of water wave and surface pressure. Figure 7 shows that the phase shifts lie between $-0.25 \pi$ and $0 \pi$, and the characteristic nodes of seabed surface pressure occur earlier than of water wave, but approach to synchronous as wave height and wave period increased.

From the observation above, the seabed surface pressure $p$ and the related phase shift $\theta$ are found all affected by wave height and wave period. Figure 8 investigates the relation between the normalized surface pressure $p / \gamma_{w} h$ and the phase shift $\theta$, where $\gamma_{w}$ is the unit weight of water. The subscripts of $\mathrm{c}, 0$ and $t$ in the figure are respectively related to the occurrence times of characteristic nodes. $p_{0}$ is defined the average with $p_{c}$ and $p_{t}$. All phase shifts are found to approach to constant as $p / \gamma_{w} h$ increased. By assuming the phase shift $\theta$ has linear relation with the inverse of $p / \gamma_{w} h$, the following relations can be found:

$$
\theta_{0}=-0.009149 \frac{\gamma_{w} h}{p_{0}}-0.02858
$$

$$
\begin{aligned}
& \theta_{t}=-0.007377 \frac{\gamma_{w} h}{p_{t}}-0.19485 \\
& \theta_{c}=-0.005286 \frac{\gamma_{w} h}{p_{c}}-0.30612
\end{aligned}
$$

\section{(3) Dynamic stresses in seabed}

In this section, the variations of dynamic stresses in seabed (normalized by seabed surface pressure $p$ ) along the depth (normalized by wave length $L$ ) are investigated. Except for the vertical stresses $\left(\Delta \sigma_{v} / p\right)$, the horizontal stresses $\left(\Delta \sigma_{h} / p\right)$ and the pore water pressure $(\Delta u / p)$, the absolute vertical effective stresses $\left(\left|\Delta \sigma_{v}^{\prime}\right| / p\right)$, the absolute horizontal effective stresses $\left(\left|\Delta \sigma_{h}^{\prime}\right| / p\right)$ and the normalized shear stresses $(\Delta \tau / p)$ are also calculated to investigate the effective dynamic stresses in seabed soil under the progressive wave actions. The equations of the effective stresses are shown as follows:

$$
\begin{gathered}
\frac{\left|\Delta \sigma_{v}^{\prime}\right|}{p}=\frac{\left|\Delta \sigma_{v}-\Delta u\right|}{p} \\
\frac{\left|\Delta \sigma_{h}^{\prime}\right|}{p}=\frac{\left|\Delta \sigma_{h}-\Delta u\right|}{p} \\
\frac{\Delta \tau}{p}=\frac{\Delta \sigma_{v}-\Delta \sigma_{h}}{2 p}=\frac{\left(\Delta \sigma_{v}-\Delta u\right)-\left(\Delta \sigma_{h}-\Delta u\right)}{2 p}=\frac{\Delta \sigma_{v}^{\prime}-\Delta \sigma_{h}^{\prime}}{2 p}
\end{gathered}
$$

Figures 9 and 10 compare the experimental results to the analytical solutions proposed by Yamamoto et al. [17]. For all normalized stresses, the theoretical value is greater than experimental result. For normalized shear stresses, due to the direction of vertical effective
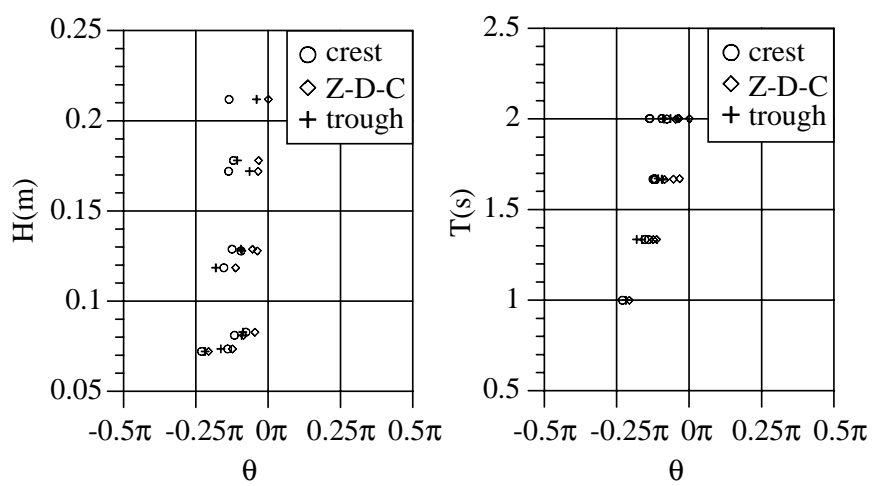

Fig. 7. Phase shifts between water wave and pressure at the seabed surface.

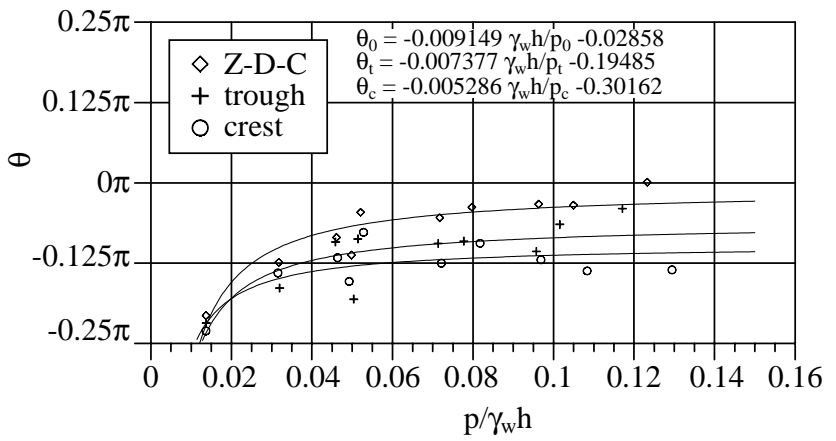

Fig. 8. Relations between normalized pressure and phase shift at seabed surface. 

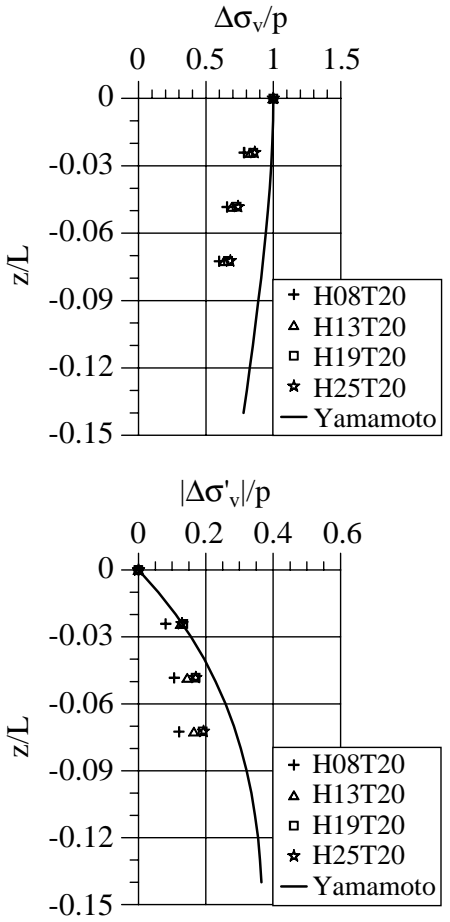
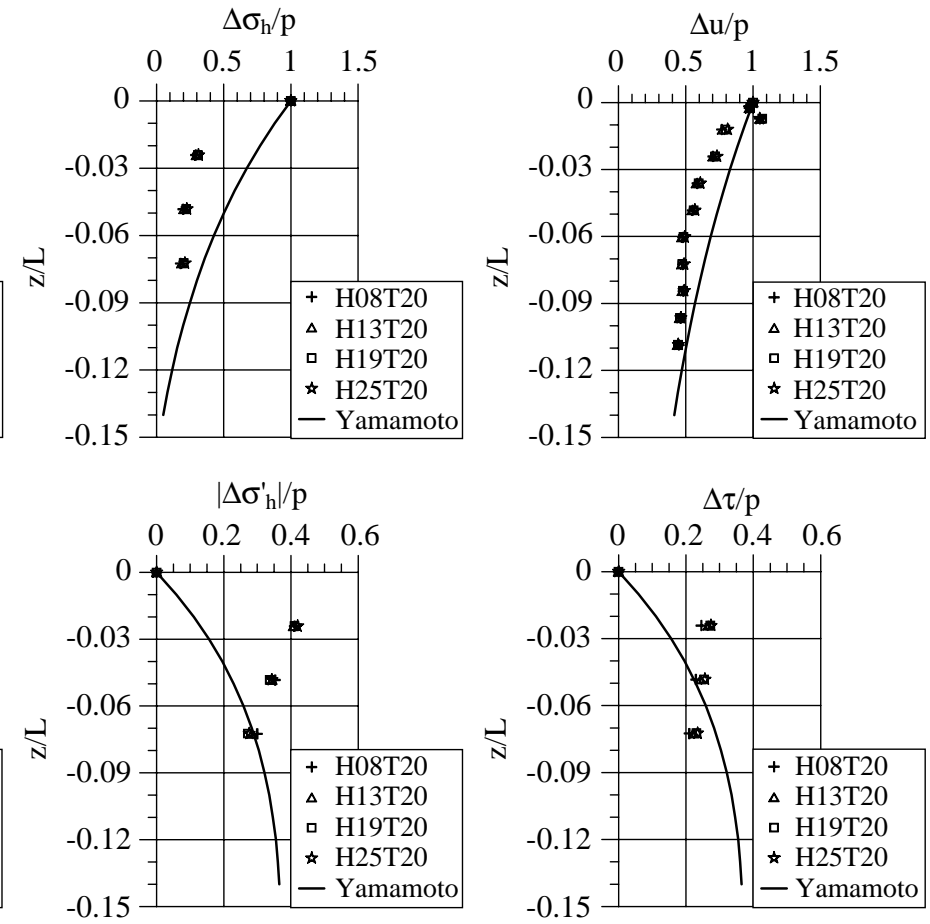

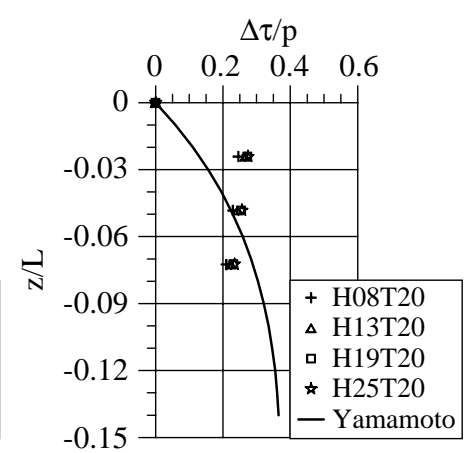

Fig. 9. Influences of wave height on dynamic stresses in seabed.
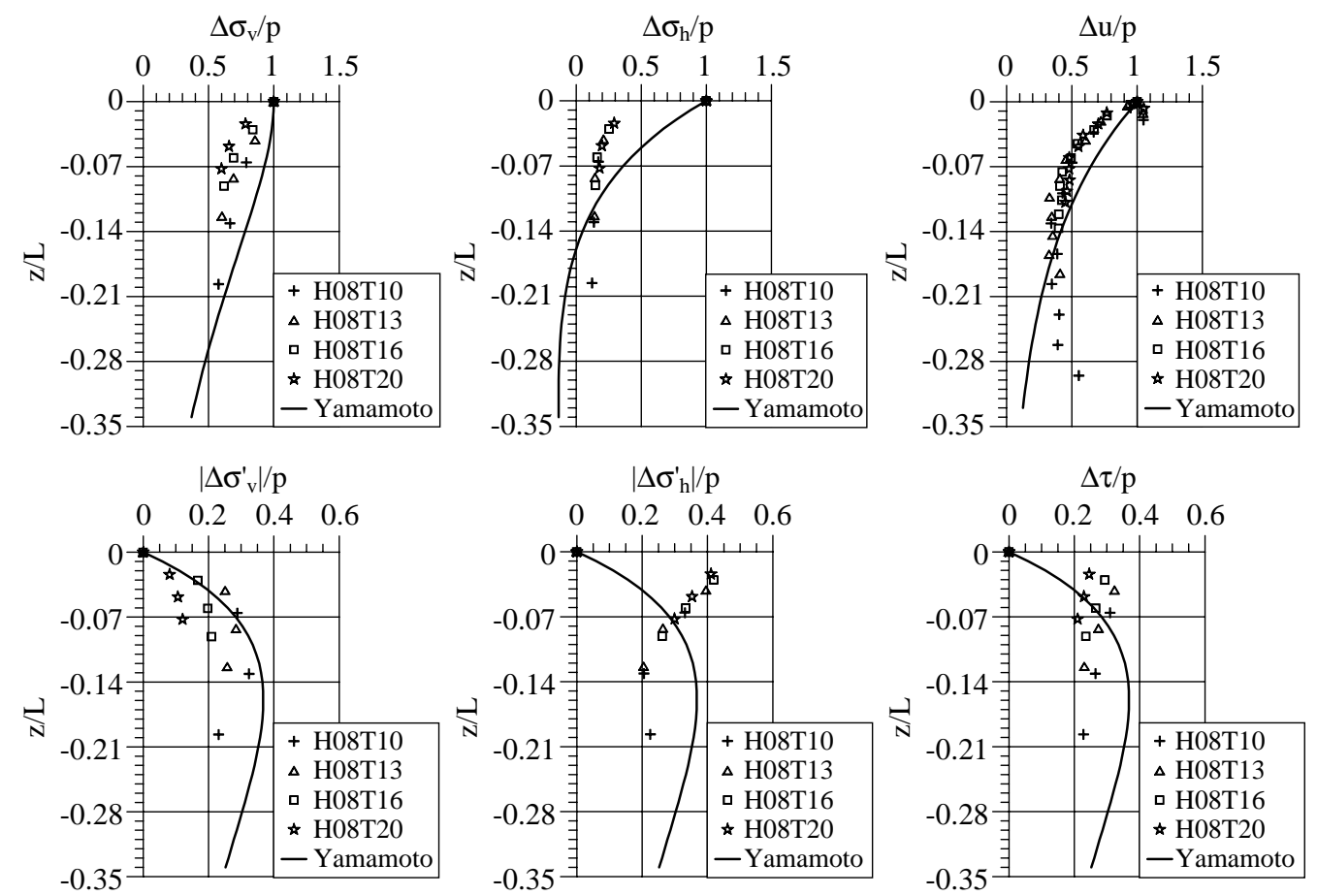

Fig. 10. Influences of wave period on dynamic stresses in seabed.

stresses is opposite to that of horizontal effective stresses, the experimental $\left|\Delta \sigma_{h}^{\prime}\right| / p$ is greater than theoretical result in shallower soil layer and causes the underestimated of the theory. Such phenomenon is because that the sandy seabed in the experiment is finite thickness and cross anisotropic and thus causes the horizontal stress smaller than theoretical value. From Figure 9, wave heights show less effect on the distribution of all stresses. Figure 10 indicates that wave periods have influences on vertical stresses and shear stresses, but 
less influences on horizontal stresses and pore water pressures.

Figures 11 and 12 show the influences of wave height and wave period on phase shifts of stresses in seabed. The occurrence times of stresses are all decayed and still the wave height plays less influence on phase shifts, instead of the phase shifts are increased as wave period decreased. The larger time delay of vertical and horizontal stresses occur at shallower layer, and approach to around $\pi / 8$. The time delay of pore water pressure is increased with depth, and the maximum measured phase shift is $3 \pi / 8$. As a conclusion, the soil mechanical properties of shallower layer under the progressive wave action will change to different from the deeper seabed soil, and should be considered as another seabed soil layer in mechanical analysis.

From the previous investigations and conclusions, the nonlinearity of water waves will decay as depth increased, the seabed surface will received quasi-linear dynamic stresses, and the occurrence time of character- istic nodes of stresses at seabed is earlier than that of waves. However, as wave pressure transmits into the seabed soil, the shallower soil is subjected to larger dynamic water pressure action which is mostly taken by pore water. As depth increased, part of the wave pressure is taken by soil particle through the frictional effect and transmits downwardly with pressure wave form, and the part born by pore water will transmit as seepage flow. The fluid motion in porous media will be affected by its porosity and pressure gradient, and cause the phase lag in pore water pressure transmission.

\section{INFLUENCE OF PHASE SHIFTS BETWEEN STRESSES IN SEABED}

In theoretical approaches, the vertical and horizontal stresses in seabed are assumed to be synchronous, which is conflicted with the current experimental results that the stresses have phase shift between each other. In this section, the influence of such phase shift

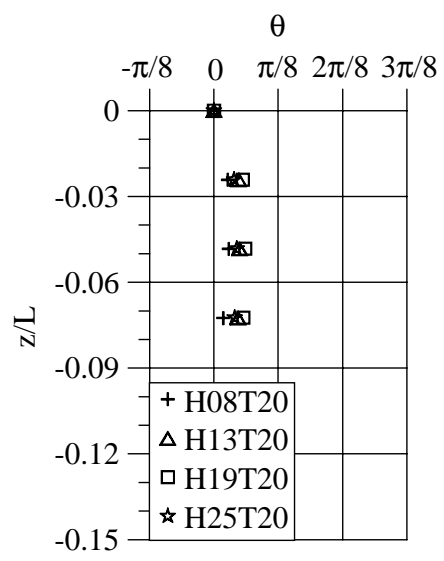

(a) Vertical stress

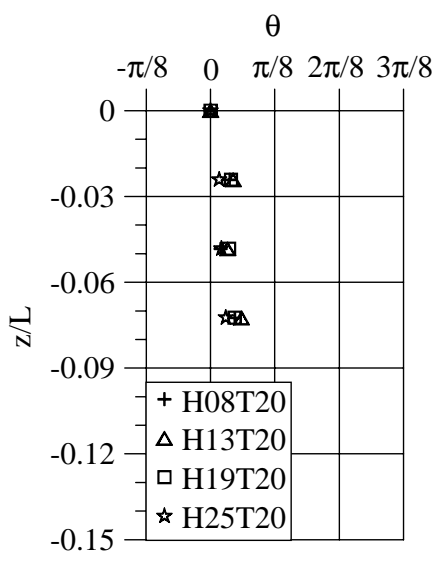

(b) Horizontal stress

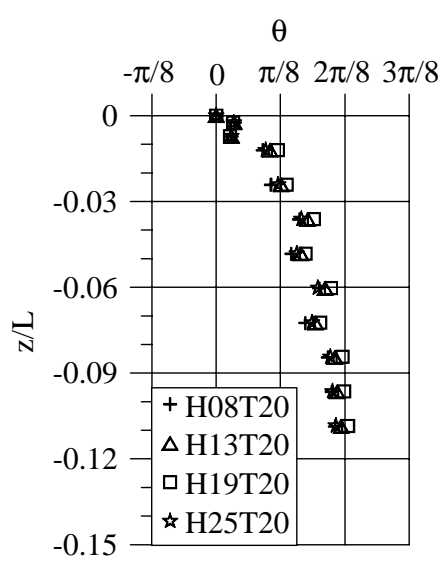

(c) Pore water pressure

Fig. 11. Influences of wave height on phase shift of each dynamic stress in seabed.

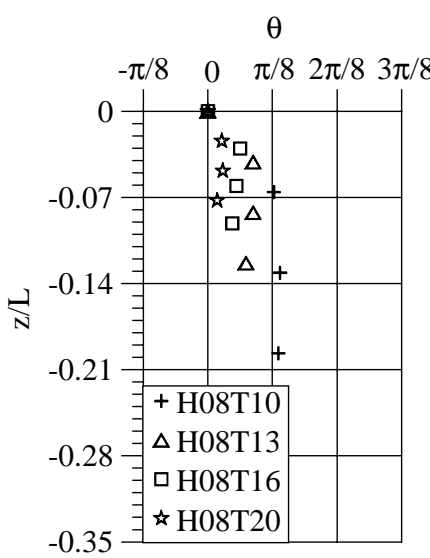

(a) Vertical stress

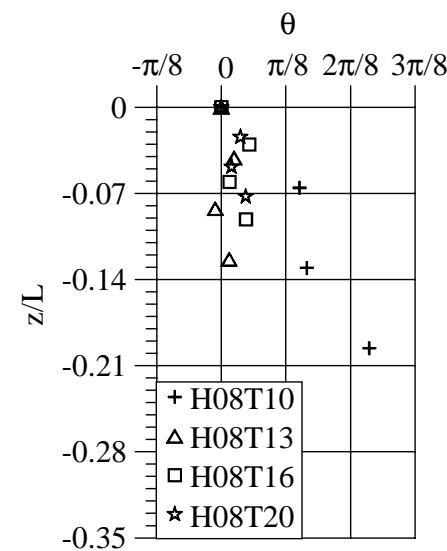

(b) Horizontal stress

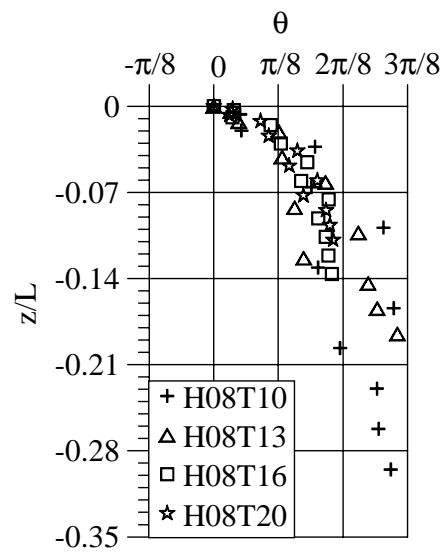

(c) Pore water pressure

Fig. 12. Influences of wave period on phase shift of each dynamic stress in seabed. 
on the total stresses subjected from water waves are investigated on time sequence.

By introducing the pressure amplitude and phase lag into the stresses in seabed soil proposed by Yamamoto et al. [17], the equations are shown as follows.

$$
\begin{aligned}
& \frac{\Delta \sigma_{v}}{p_{0}}=c_{\Delta \sigma_{v}} \cdot \cos \left(k x-\omega t-\theta_{\Delta \sigma_{v}}\right) \\
& \frac{\Delta \sigma_{h}}{p_{0}}=c_{\Delta \sigma_{h}} \cdot \cos \left(k x-\omega t-\theta_{\Delta \sigma_{h}}\right) \\
& \frac{\Delta u}{p_{0}}=c_{\Delta u} \cdot \cos \left(k x-\omega t-\theta_{\Delta u}\right)
\end{aligned}
$$

where, $c_{\Delta \sigma_{v}}, c_{\Delta \sigma_{h}}, c_{\Delta u}, \theta_{\Delta \sigma_{v}}, \theta_{\Delta \sigma_{h}}$ and $\theta_{\Delta u}$ are mean value of the amplitude and phase shift of stresses calculated from experimental data which are shown in Figures 9 to 12.
Taking as an example, Figures 13 and 14 show respectively the stress paths and effective stress paths in the case of H25T20. In the stress paths in Figure 13, column (a) is the measured data, columns (b) and (c) are the theoretical results without and with phase shift between the dynamic vertical and horizontal stresses, $\mathrm{i}$. e. $\theta_{\Delta \sigma_{v}}=\theta_{\Delta \sigma_{h}}=0$ and $\theta_{\Delta \sigma_{v}} \neq 0, \theta_{\Delta \sigma_{h}} \neq 0$, respectively. The figures show that phase shift has dominant influence on the stress path.

Figure 14 shows the effective stress paths in seabed soil, column (a) is the measured data, column (b) takes into account the phase shift between the dynamic vertical and horizontal stresses but assumes the pore pressure is synchronously with the dynamic vertical stress (i.e. $\theta_{\Delta \sigma_{v}}=\theta_{\Delta u} \neq \theta_{\Delta \sigma_{h}}$ ), and column (c) considers all phase shifts between the stresses(i.e. $\theta_{\Delta \sigma_{v}} \neq \theta_{\Delta u} \neq$ $\left.\theta_{\Delta \sigma_{h}}\right)$. By comparing each column, the results show that the phase shift of pore pressure has great influence on the stress paths and should be taken into account. (i) $\mathrm{z}=-10 \mathrm{~cm}$

(ii) $\mathrm{z}=-20 \mathrm{~cm}$

(iii) $\mathrm{z}=-30 \mathrm{~cm}$

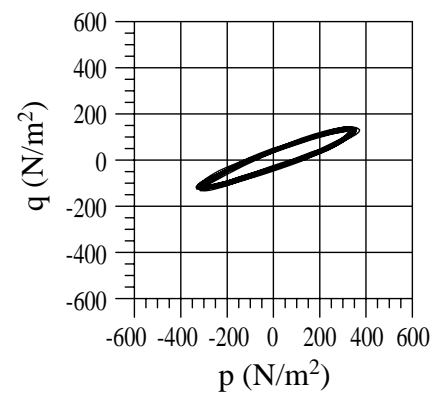

(a) Measured data

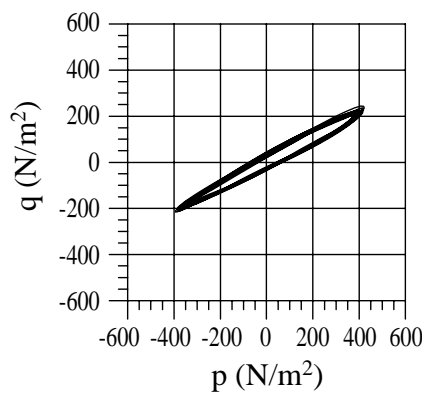

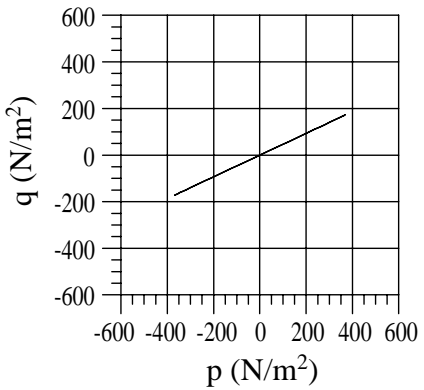
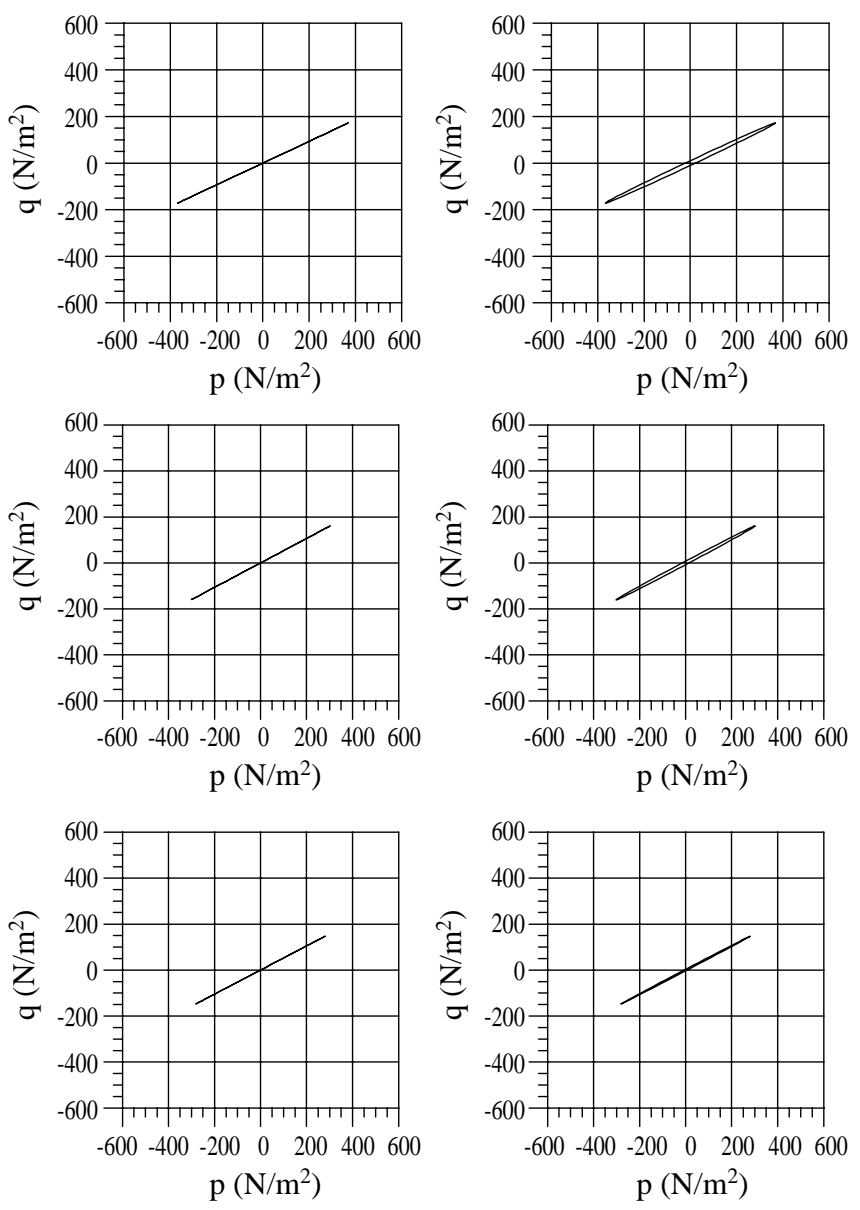

(b) $\theta_{\Delta \sigma_{v}}=\theta_{\Delta \sigma_{h}}=0$

(c) $\theta_{\Delta \sigma_{v}} \neq 0, \theta_{\Delta \sigma_{h}} \neq 0$

Fig. 13. Stress paths in seabed soil induced by progressive waves. 
(i) $\mathrm{z}=-10 \mathrm{~cm}$

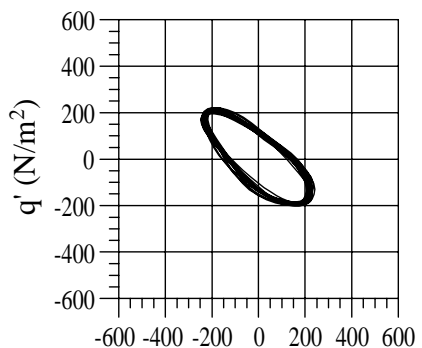
$\mathrm{p}^{\prime}\left(\mathrm{N} / \mathrm{m}^{2}\right)$

(ii) $\mathrm{z}=-20 \mathrm{~cm}$

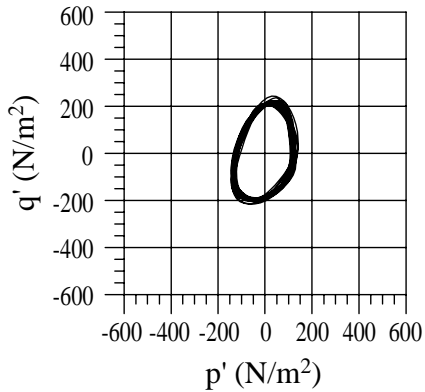

(iii) $\mathrm{z}=-30 \mathrm{~cm}$

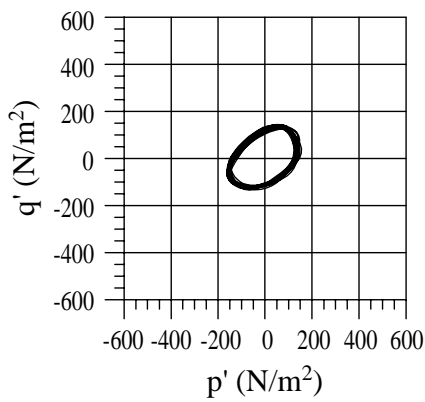

(a) Measured data
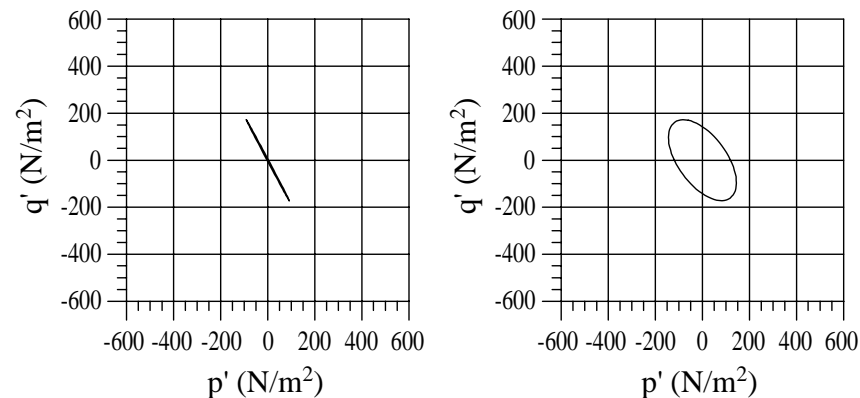

$-600-400-200 \quad 0 \quad 200400600$ $\mathrm{p}^{\prime}\left(\mathrm{N} / \mathrm{m}^{2}\right)$
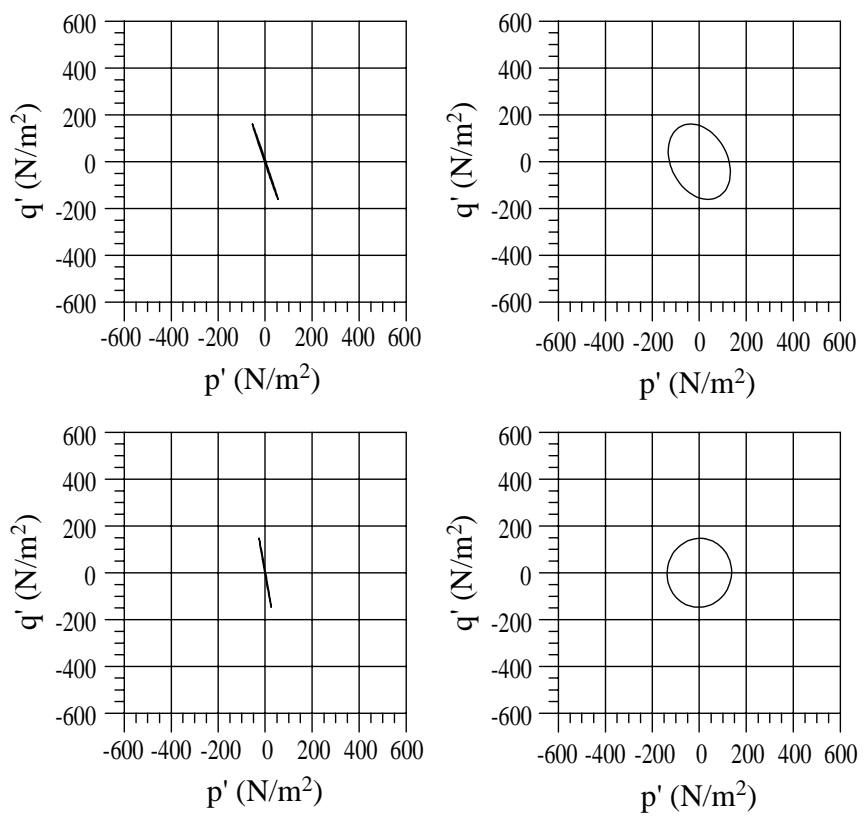

(b) $\theta_{\Delta \sigma_{v}}=\theta_{\Delta u} \neq \theta_{\Delta \sigma_{h}}$ (c) $\theta_{\Delta \sigma_{v}} \neq \theta_{\Delta u} \neq \theta_{\Delta \sigma_{h}}$

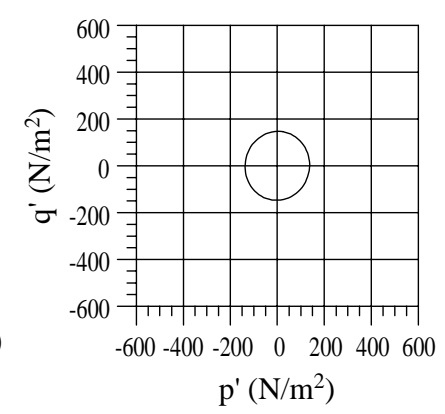

Fig.14. Effective stress paths in seabed soil induced by progressive waves.
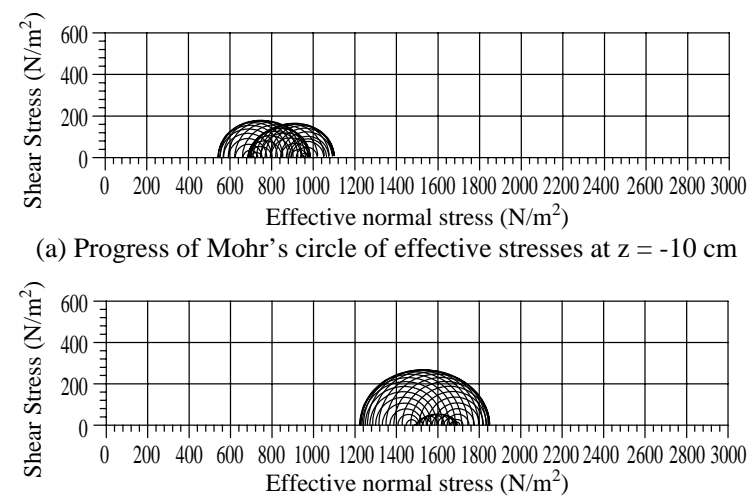

(b) Progress of Mohr's circle of effective stresses at $\mathrm{z}=-20 \mathrm{~cm}$

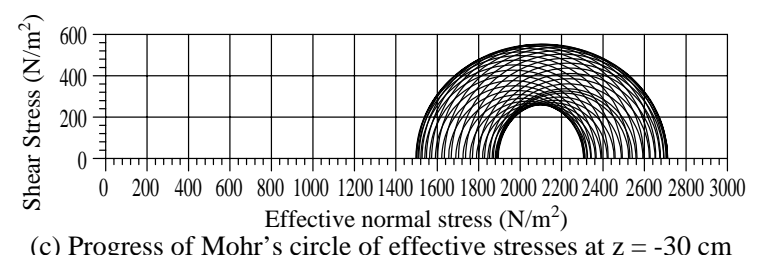

Fig. 15. Progress of Mohr's circle of effective stresses in seabed induced by progressive waves.

\section{TOTAL STRESS BEHAVIOR IN SEABED FROM MOHR'S CIRCLES}

From the results discussed above, the natural deposit seabed under the progressive wave action will subject the actions of initial shear stress and dynamical forces. To understand the total stress behavior in seabed, Mohr's circle of total effective stresses was used. Figure 15 shows the periodic change of Mohr's circle of progressive wave-induced soil stresses in the seabed in case H25T20. The results were calculated from the measurements of initial static stresses, instantaneous dynamic stresses, and phase shifts. The figure shows the magnitude of total shear stress increases as the seabed depth increases, and the Mohr's circle of shallower layer is much closed to failure which is caused by larger dynamic pore water pressure action from waves indicating the initial shear stress induced by anisotropic property of natural deposit seabed will affect the soil resistant strength for dynamic wave forces. 


\section{CONCLUSIONS}

In this study, a series of 2-D hydraulic model tests have been carried out to investigate the duration behavior of seabed stresses induced by progressive waves, several major achievements are concluded as follows:

1 . The occurrence times of characteristic nodes of water waves and wave pressure at seabed surface are not synchronous. In our experiments, the maximum phase shift may approach to $-\pi / 4$. This is different from the current theories that assume the waves and pressures within seabed are synchronous.

2. Due to the anisotropic property of natural deposit seabed soil, the progressive waves induced vertical stress and horizontal stress have different transmit speeds and have phase shift between them.

3 . The pore pressure induced by water waves will cause the stress transmission in shallower soil has different properties with deeper seabed soil. The results show that when analyze the seabed stability under the progressive waves action, the stress transmission of shallow soil should be carefully treated.

4. The transmission of pore water pressure acts like seepage flow and has phase shift to seabed surface pressure with maximum value of $3 \pi / 8$.

5. The phase shifts between the stresses in seabed have influences on the stress paths in sandy seabed, and the phase shift of pore water pressure takes the role.

6 . The initial shear stress of natural deposit seabed greatly increases the total shear stress subjected by the seabed soil, their influences at seabed stability should be studied further.

As a conclusion, the initial shear stress, and anisotropic and non-homogeneous properties of natural deposited seabed will affect the transmission of waveinduced stresses, and should be taken into account in the stability analysis of seabed.

\section{ACKNOWLEDGEMENT}

This research was funding by National Science Council, Taiwan under the project entitled "The Study of the Dynamic Behavior in Nearshore Structures beneath Foundation Soil Due to Wave Loading Action (I) " with project number of NSC-91-2211-E-019-013, and with the cooperation of the Harbor and Marine Technology Center. The authors want to express their sincerely appreciations to all of them.

\section{REFERENCES}

1. Biot, M.A., "General Theory of Three-Dimensional Consolidation," Journal of Applied Physics, Vol. 12, pp. 155-164 (1941).
2. Demars, K.R. and Vanover, E.A., "Measurement of Wave-Induced Pressures and Stresses in a Sandbed," Marine Geotechnology, Vol. 6, No. 1, pp. $29-59$ (1985).

3. Goda, Y., Random Seas and Design of Maritime Structures, World Scientific, NJ (2000).

4. Jeng, D.S., "Wave-Induced Liquefaction Potential in a Cross-Anisotropic Seabed," Journal of the Chinese Institute of Engineers, Vol. 19, No. 1, pp. 59-70 (1996).

5. Jeng, D.S., "Wave-Induced Sea Floor Dynamics," Applied Mechanics Reviews, Vol. 56, No. 4, pp. 407-429 (2003).

6. Jeng, D.S. and Cha, D.H., "Effects of Dynamic Soil Behavior and Wave Non-linearity on the Wave-Induced Pore Pressure and Effective Stresses in Porous Seabed," Ocean Engineering, Vol. 30, pp. 2065-2089 (2003).

7. Jeng, D.S. and Seymour, B.R., "Response in Seabed of Finite Depth with Variable Permeability," Journal of Geotechnical and Geoenvironmental Engineering, Vol. 123, No. 10, pp. 902-911 (1997).

8. Kitano, T. and Mase, H., "Wave-Induced Porewater Pressure in a Seabed with Inhomogeneous Permeability," Ocean Engineering, Vol. 28, pp. 279-296 (2001).

9. Le Méhauté, B. An Introduction to Hydrodynamics and Water Waves, Springer-Verlag, Berlin (1976).

10. Lee, T.L., Tsai, C.P., and Jeng, D.S., "Ocean Waves Propagating over a Coulomb-damped Poroelastic Seabed of Finite Thickness: an Analytical Solution," Computers and Geotechnics, Vol. 29, pp. 119-149 (2002).

11. Madsen, O.S., "Wave-Induced Pore Pressures and Effective Stresses in a Porous Bed," Géotechnique, Vol. 28, No. 4, pp. 337-393 (1978).

12. Okusa, S., "Measurements of Wave-Induced Pore Pressure in Submarine Sediments under Various Marine Conditions," Marine Geotechnology, Vol. 6, No. 2, pp. 119-144 (1985).

13. Okusa, S. and Uchida, A., "Pore-Water Pressure Change in Submarine Sediments due to Waves," Marine Geotechnology, Vol. 4, No. 2, pp. 145-160 (1980).

14. Sassa, S. and Sekiguchi, H., "Wave-Induced Liquefaction of Beds of Sand in Centrifuge," Géotechnique, Vol. 49, No. 5, pp. 621-638 (1999).

15. Seymour, B.R., Jeng, D.S., and Hsu, R.C., "Transient Soil Response in a Porous Seabed with Variable Permeability," Ocean Engineering, Vol. 23, No. 1, pp. 27-46 (1996).

16. Tsui, Y. and Helfrich, S.C., "Wave-Induced Pore Pressure in Submerged Sand Layer," Journal of Geotechnical Engineering, Vol. 109, No. 4, pp. 603-618 (1983).

17. Yamamoto, T., Koning, H.L., Sellmeijer, H., and Hijum E.V., "On the Response of a Poro-Elastic Bed to Water Waves," Journal of Fluid Mechanics, Vol. 87, No. 1, pp. 193-206 (1978). 
18. Yuhi, M. and Ishida, H., "Simplified Solutions for WaveInduced Response of Anisotropic Seabed," Journal of Waterway, Port, Coastal and Ocean Engineering, Vol. 128, No. 1, pp. 46-50 (2002).

19. Zen, K., Jeng, D.S., Hsu, J.R.C., and Ohyana, H., "WaveInduced Seabed Instability: Difference between Liquefaction and Shear Failure," Soils and Foundations, Vol. 38, No. 2, pp. 37-47 (1998).

20. Zen, K. and Yamazaki, H., "Mechanism of WaveInduced Liquefaction and Densification in Seabed,"
Soils and Foundations, Vol. 30, No. 4, pp. 90-104 (1990a).

21. Zen, K. and Yamazaki, H., "Oscillatory Pore Pressure and Liquefaction in Seabed Induced by Ocean Waves," Soils and Foundations, Vol. 30, No. 4, pp. 147-161 (1990b).

22. Zen, K. and Yamazaki, H., "Field Observation and Analysis of Wave-Induced Liquefaction in Seabed," Soils and foundations, Vol. 31, No. 4, pp. 161-179 (1991). 